\title{
GIS based Flood Vulnerability Studies for Ife Central Local Government Area, Osun State, Nigeria
}

\author{
Ijaware V. A. \\ Department of Surveying and Geoinformatics, Federal University of Technology, Akure, Ondo State, Nigeria \\ Corresponding Author: vaijaware@futa.edu.ng
}

https://doi.org/10.36263/nijest.2020.01.0184

\begin{abstract}
Flood has negatively affected Ife Central Local Government Area of Osun State, Nigeria. This work is aimed at mapping the vulnerability of the area flood. Its objectives addressed the ranking of various natural and artificial factors causing flood, the determination and delineation of vulnerability to flood in the study area. Using remote sensing and GIS techniques, coordinates of flooded sites were acquired with Global Navigation Satellite Systems receiver; Landsat 8 data were acquired from the USGS website. To map land use, elevation data were acquired from the Shuttle Radar Topographic Mission Digital Elevation Models, soil data was obtained from the Nigerian Geological Survey website, and rainfall data was acquired from Tropical Rainfall Measuring Mission satellite. Using Pairwise Comparison, the various weights of factors constituting flood in the area were acquired. Weighted Linear Combination and Analytical Hierarchical Process was used in producing the flood hazard and flood vulnerability maps. ArcGIS10.2 Software was used in spatial and attribute data acquisition, processing, and information presentation. The Pairwise Comparison method adopted was validated and observed to have a consistency ration of 0.003 . Results obtained show that $9.2 \%$ of the study area is highly prone to flood hazards, $20.4 \%$ is prone to flood hazard and $44.3 \%$ is moderately prone to flood hazard. The method adopted correctly identifies all existing flood incidence areas within the flood-prone areas in the hazard map. The maps produced will serve as an effective tool to aid the prevention and mitigation of flood disaster in the flood-prone area.
\end{abstract}

Keywords: AHP, Flood Vulnerability, Remote Sensing, GIS, Shuttle Radar Topographic Mission

\subsection{Introduction}

Flooding is the overflow of water where it is not wanted, a scenario that occurs when part of the earth's surface which is usually dry is covered with water due to high rainfall or other water body overflow substances. Flood is a major disaster that affects many countries of the world annually. The threat to lives and properties by flood is an annual event in urban centres of many countries. Flooding is frequently triggered by heavy rainfall on relatively flat terrains, failure of reservoirs, volcano, snow and/or glaciers melting, etc. To evaluate the impact of flood in a society, a flood risk assessment is usually carried out. Flood risk assessment is based on the history of several variables which include; rainfall, river flow, tidal surge information, topography, flood-control measures, and alterations due to flood plain construction and growth etc. Amidst the variables that cause flooding, heavy rainfall invariably precedes them in Nigeria. Other causes of flooding include moderate to serious water winds, uncommon elevated tides, tsunamis caused by undersea earthquakes, dam breaks or failures, levees, retention ponds or lakes, and other water-retaining infrastructure. In towns and outskirts, pavement and rooftops contribute to the inability of the soil to absorb rainfall, thereby leading to flooding in the Urban Centres (Dor, 2017).The attendant negative effects of floods on man and his environment make it quite important to map vulnerability to flooding.

Flood disasters have affected the lives of several people more than most natural disasters (Klemas, 2015; Komolafe et al., 2015; Orimoogunje et al., 2016). The negative effects of flooding are most times irreversible. Several works have been done to identify flood risk, map flood hazard, and assess vulnerability to flooding globally and locally. Of significance is the review of Klemas (2015) on the 
remote sensing of flood and flood-prone areas. Modelling techniques for forecasting vulnerability to flooding were discussed and rules of thumb were represented for forecasting vulnerability to flooding; part of the methods presented are implemented in this research. Furthermore, Ouma and Tateishi (2014) presented a methodological overview of multi-parametric AHP and GIS techniques in carrying out an Urban flood vulnerability assessment and risk mapping.

Unfortunately, the repetitive flooding of Ile-Ife has continued to grow regardless of the existence of literature to curb its effects. The problem has been that of non-implementation of existing principles, part of which includes the assessment of vulnerability to flooding, and the implementation of knowledge gained from such assessment. Negative effects of flooding have continued to impact lives and properties in Ife Central LGA. Alfred (2018) explained a situation where communities within Ife Central LGA such as Aserifa, Damico, Ede Road, Mayfair and Parakin were impacted by the flood disaster in the year 2018, leading to the submerging underwater of several shops and homes. This work adopts the multi-parametric AHP and GIS techniques of Ouma and Tateishi (2014) using AHP and Multi-Criteria Decision Analysis to map flood hazard and determine vulnerability to flooding in Ife Central LGA.

\subsection{Methodology}

\subsection{Study Area}

Ife central as shown in Figure 1 is a Local Government Area in Osun State, having its headquarters in the city of Ile Ife to the south of the area, which is part of Ife (an ancient Yoruba city in south-western Nigeria). Ife central LGA has a population of 167, 254 according to 2006 population census and with an area of 110 square kilometres and approximately lies within Latitudes and Longitudes $\left(7^{\circ} 34^{\prime}\right.$, $\left.4^{\circ} 29^{\prime}\right),\left(7^{\circ} 37^{\prime}, 4^{\circ} 32^{\prime}\right),\left(7^{\circ} 32^{\prime}, 4^{\circ} 35^{\prime}\right)$, and $\left(7^{\circ} 28^{\prime}, 4^{\circ} 34^{\prime}\right)$.

The climate of Ife Central LGA is characterized after the tropical rainforest of rainy wet and dry seasons. The rainy season lasts between April and October, while the dry season extends from November to March annually. The annual rainfall of Ife-Central is around $1340 \mathrm{~mm}$ and the mean annual temperature fluctuates around $26.2^{\circ} \mathrm{C}$ (Climate-Data.org, n.d.). The elevation ranges between $236 \mathrm{~m}-449 \mathrm{~m}$ above mean sea level.

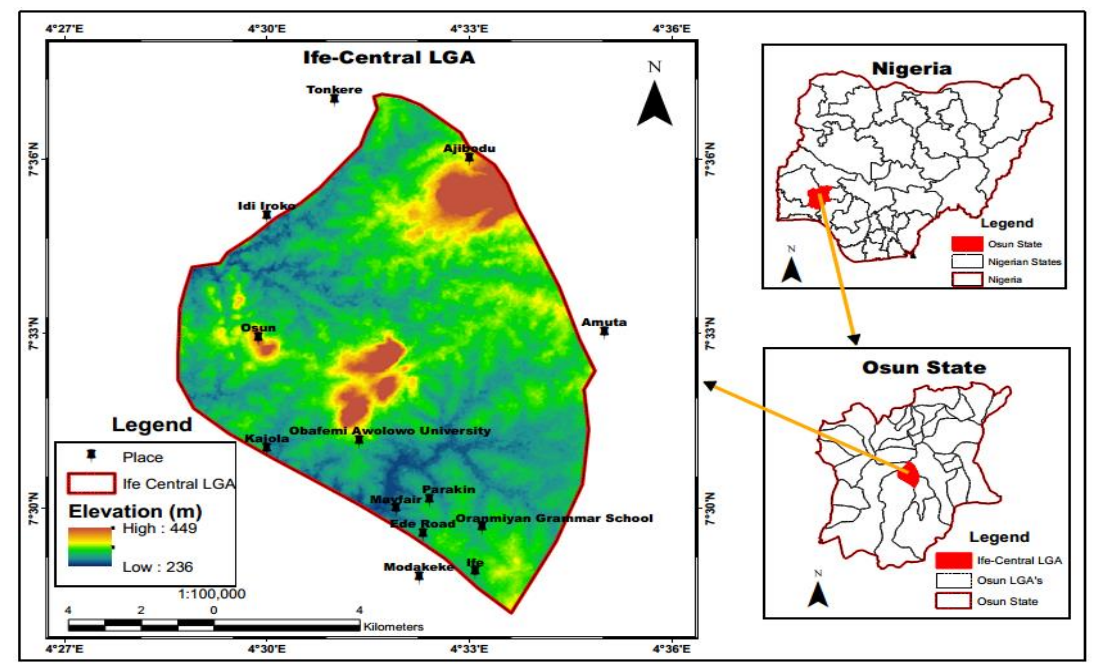

Figure 1: Study area map

\subsection{Data Source}

Coordinates of places with prior history of flooding within the study area were acquired using GARMIN Etrex 20 handheld GNSS receiver. Shuttle Radar Topography Mission (SRTM) Digital Elevation Model (DEM) data was acquired from the United States Geological Survey (USGS) website; annual rainfall data for the year 2018 was obtained from Tropical Rainfall Measuring Mission (TRMM) satellite data, Landsat 8 was acquired from the USGS website for land use/land cover mapping; Soil vector data was acquired from the Nigerian Geological Survey, and the administrative boundary was obtained from the Office of the Surveyor-General of the Federation 
(OSGOF). Table 1 shows the type of the data acquired for the flood mapping, their format, scale/resolution, year of acquisition and source.

Table 1: Flood mapping data sources

\begin{tabular}{|c|c|c|c|c|c|}
\hline $\mathrm{S} / \mathrm{N}$ & Type & Format & Scale/ Resolution & Year & Source \\
\hline 1 & $\begin{array}{l}\text { Shuttle Radar Topography } \\
\text { Mission }\end{array}$ & Digital & $30 \mathrm{~m}$ & 2018 & United States Geological Survey (USGS) \\
\hline 2 & Landsat OLI/TIRS & Digital & $30 \mathrm{~m}$ & 2018 & United States Geological Survey (USGS) \\
\hline 3 & Rainfall & Digital & $\begin{array}{l}\text { 30m/ Annual } \\
\text { Rainfall Data }\end{array}$ & 2018 & $\begin{array}{l}\text { Tropical Rainfall Measuring Mission } \\
\text { (TRMM) }\end{array}$ \\
\hline 4 & Soil Map & Digital & $\begin{array}{l}\text { Vector File/ No } \\
\text { Resolution }\end{array}$ & & Nigerian Geological Survey \\
\hline 5 & Administrative Map & Digital & $\begin{array}{l}\text { Vector File/ No } \\
\text { Resolution }\end{array}$ & 2017 & $\begin{array}{l}\text { Office Of The Surveyor General Of The } \\
\text { Federation (OSGOF) }\end{array}$ \\
\hline 6 & GPS Coordinates & Digital & & 2019 & Field Data \\
\hline
\end{tabular}

\subsection{Methods}

Figure 2 shows the method adopted for this study.

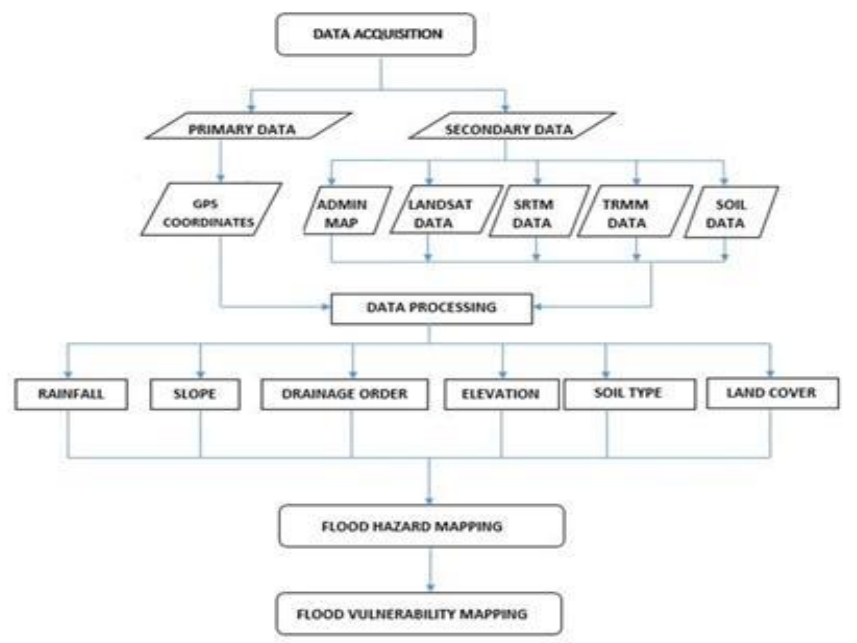

Figure 2: Flood hazard and vulnerability mapping methodology flow

2.3.1. Flood risk criteria data acquisition and processing

Ife-Central L.G.A, Osun State, and Nigeria shapefile were identified from the Administrative vector file acquired from OSGOF to produce the study area map shown in Figure 1 on ArcGIS software. Figure 2 shows the flow of methods applied in carrying out the flood hazard and vulnerability mapping. UTM Coordinates of existing flood sites were acquired using the GARMIN Etrex 20 handheld GNSS receiver. The elevations of the study area were mapped out from the obtained SRTM 30M DEM data in ArcGIS 10.4.1 environment. The Digital Elevation Model (DEM) of the study area was used to extract slope and drainage as input in the analysis. The slope of the area was mapped from the DEM extracted from SRTM using the spatial analysis tool of the ArcGIS toolbox. The rainfall data were extracted from the TRMM satellite data. The X, Y, and Z (Rainfall) were imported into the ArcMap environment. Inverse Distance Weighted (IDW) spatial interpolation technique was employed in the arc-tool box to produce a surface map of the rainfall.

Soil types of the study area were extracted from the soil map of the Nigerian Meteorological Agency (NIMET). The soil map of the area was further reclassified based on the infiltration rate to incorporate the Spatio-temporal infiltration rate of the area into the flood hazard and vulnerability determination process. The land use/land cover map for the study area was produced from Landsat 8 . The Landsat data acquired in 2018 was processed in ArcGIS 10.4.1 environment. Having obtained data of different coordinate systems from disparate sources, all the data were converted into Universal Transverse Mercator (UTM) WGS84 datum in the ArcMap environment to have a uniform coordinate system and to aid correct overlay of the data. 


\subsubsection{Flood risk criteria ranking}

Six (6) of the different criteria identified were considered as the main factors necessary for assessing flood risk and measuring its hazard for the study. The factors include; elevation, drainage density, precipitation amount (rainfall), slope, soil type, and land cover. All criteria were reclassified, and a linear function was used to assign preference value to different classes. The unified preference value ranges from 1 to 4 , which is equivalent to 25 to 100 . 1(25) is the minimum preference value and 4(100) signifies high preference value. The unified preference values for classes in every criterion are shown in Table 2 to Table 7.

\section{Elevation:}

The elevation of the study area derived from SRTM DEM is shown in Figure 3. The elevation was reclassified based on their effect on flooding. Areas with the least elevation were ranked 4 while areas with the highest elevation were ranked 1. Red in Figure 3 shows elevation ranges between 236m$270 \mathrm{~m}$, pink shows elevation between of $271 \mathrm{~m}-298 \mathrm{~m}$, yellow shows elevation within $299 \mathrm{~m}-353 \mathrm{~m}$ and Blue shows elevation range of $354 \mathrm{~m}-449 \mathrm{~m}$. Table 2 shows the elevation ranges, preference value, and flood hazard class of the elevation criteria.

Table 2: Unified preference value for elevation

\begin{tabular}{llll}
\hline Elevation $(\mathrm{m})$ & Preference Value & Unified Value & Flood Hazard class \\
\hline $236-270$ & 4 & 100 & Very high \\
$271-298$ & 3 & 75 & High \\
$299-353$ & 2 & 50 & Moderate \\
$354-449$ & 1 & 25 & Low \\
\hline
\end{tabular}

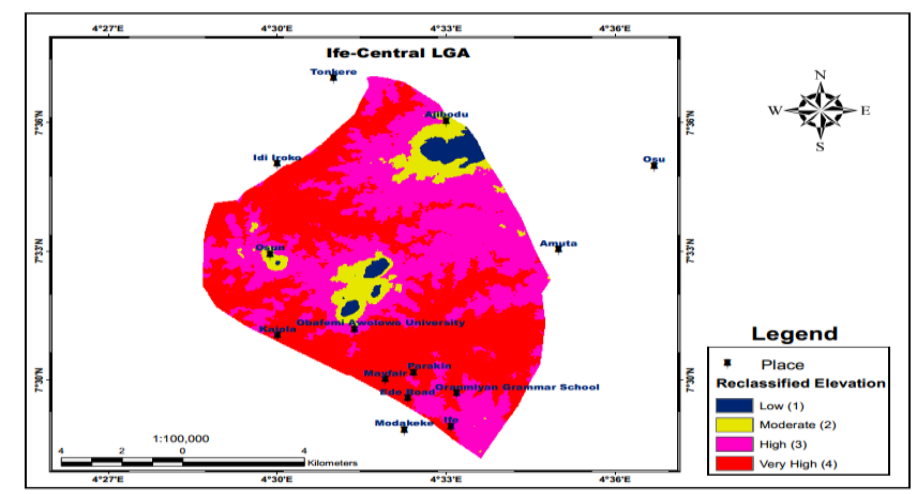

Figure 3: Elevation of the study area

Slope:

Figure 4 shows the slope of the reclassified slope map of the study area as derived from the SRTM DEM using ArcGIS software. Table 3 shows the preference value of degrees of slope areas with the lowest degree of slope (0-23) were ranked high preference value for slope while areas with 55-85 were ranked lowest.

Table 3: Unified preference value for degree of slope

\begin{tabular}{llll}
\hline Slope (degree) & Preference Value & Unified Value & Flood Hazard class \\
\hline $0-23$ & 4 & 100 & Very high \\
$24-38$ & 3 & 75 & High \\
$39-54$ & 2 & 50 & Moderate \\
$55-85$ & 1 & 25 & Low \\
\hline
\end{tabular}




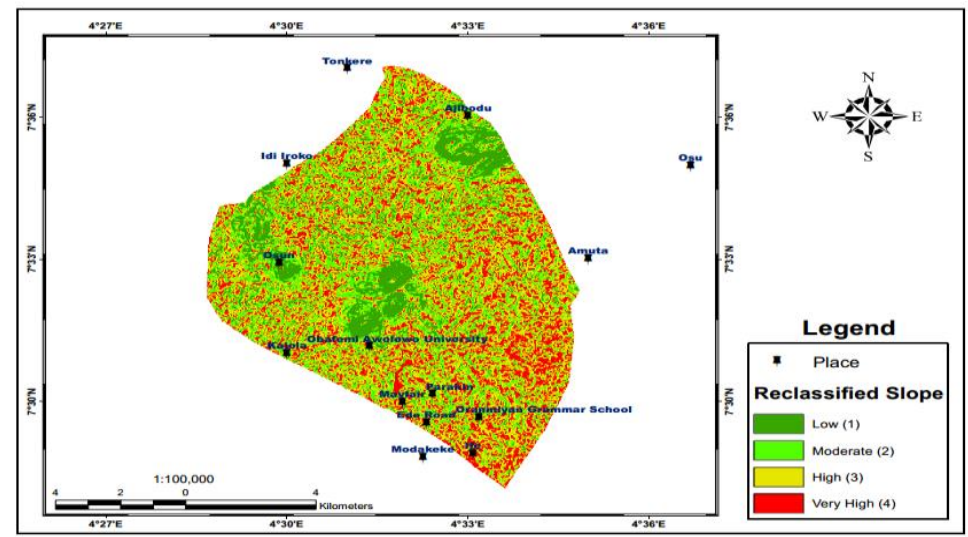

Figure 4: Slope map of the study area

\section{Drainage density:}

A drainage density map was produced for the study area and the layer was further reclassified in four preference classes. Areas with very low drainage density are dry areas which were ranked as 4 and those with very high drainage density are wet areas, which were ranked with a value of 1 as depicted in Table 4 and Figure 5. The higher the density, the higher the catchment area is prone to flood, resulting in sedimentation at the lower grounds.

Table 4: Unified preference value for drainage density

\begin{tabular}{llll}
\hline Drainage density $(\mathrm{m})$ & Preference Value & Unified Value & Flood Hazard class \\
\hline $1-108$ & 1 & 25 & Low \\
$109-173$ & 2 & 50 & Moderate \\
$174-239$ & 3 & 75 & High \\
$240-358$ & 4 & 100 & Very high \\
\hline
\end{tabular}

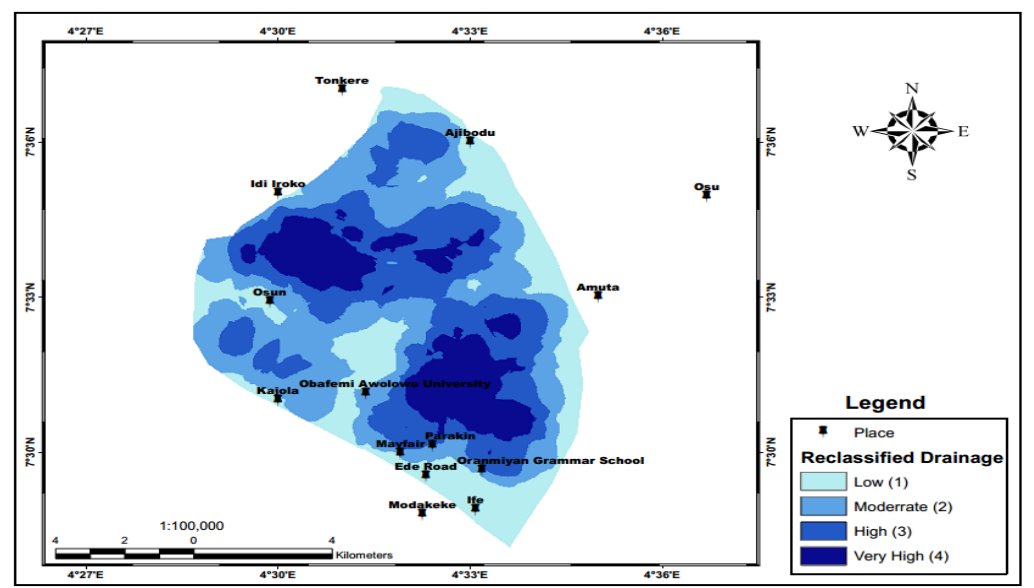

Figure 5: Drainage density map of study area

\section{Rainfall:}

The annual rainfall for the year 2018 ranges between $1278 \mathrm{~mm}-1344 \mathrm{~mm}$. The rainfall was reclassified based on the ranges. The preference value was ranked based on the increase of precipitation values. Places with high rainfall are more prone to flood while areas with a low amount of rainfall are less prone to flood. The rainfall distribution and unified preference values are shown in Table 5 and Figure 6.

Table 5: Unified preference value for rainfall distribution

\begin{tabular}{llll}
\hline Rainfall distribution $(\mathrm{mm})$ & Preference Value & Unified Value & Flood vulnerability class \\
\hline $1,278-1,290$ & 1 & 25 & Low \\
$1,291-1,307$ & 2 & 50 & Moderate \\
$1,308-1,330$ & 3 & 75 & High \\
$1,331-1,334$ & 4 & 100 & Very high \\
\hline
\end{tabular}




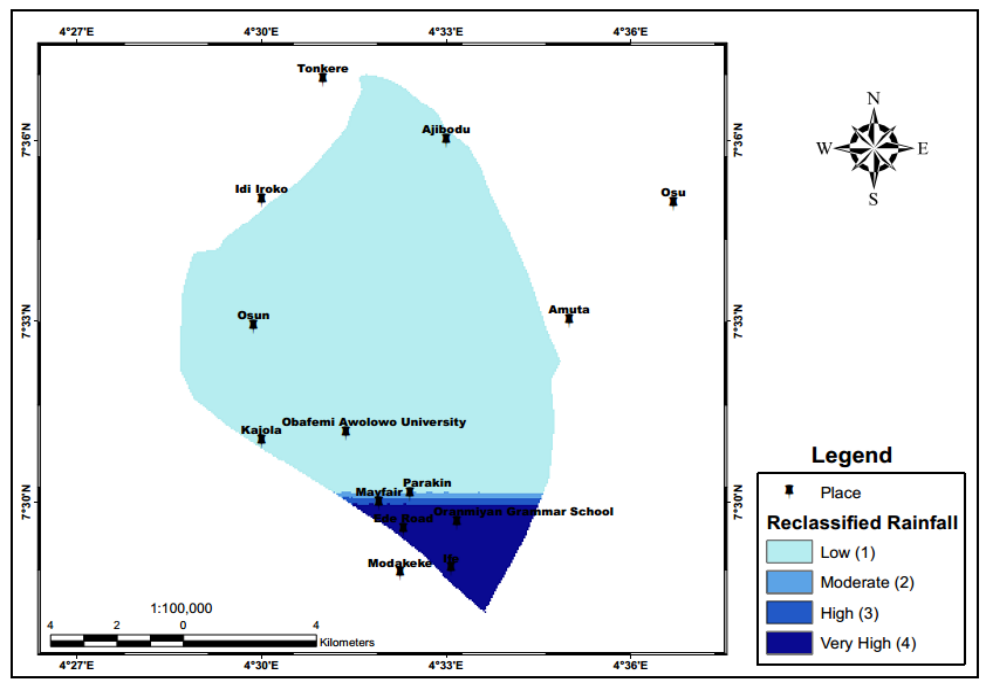

Figure 6: Reclassified rainfall distribution map

Soil:

The soil map of the study area shows two major types of soil, which are loam and sandy loam as shown in Figure 7. Preference value was assigned to soil types based on their infiltration rate as shown in Table 6.

Table 6: Unified preference value for soil type

\begin{tabular}{lllll}
\hline Soil Type & Infiltration Rate $\left(\mathrm{mmhr}^{-1}\right)$ & Preference Value & Unified Value & Flood vulnerability class \\
\hline Sandy Loam & $20-30$ & 1 & 25 & Low \\
Loamy Sand & $15-20$ & 2 & 50 & Moderate \\
\hline
\end{tabular}

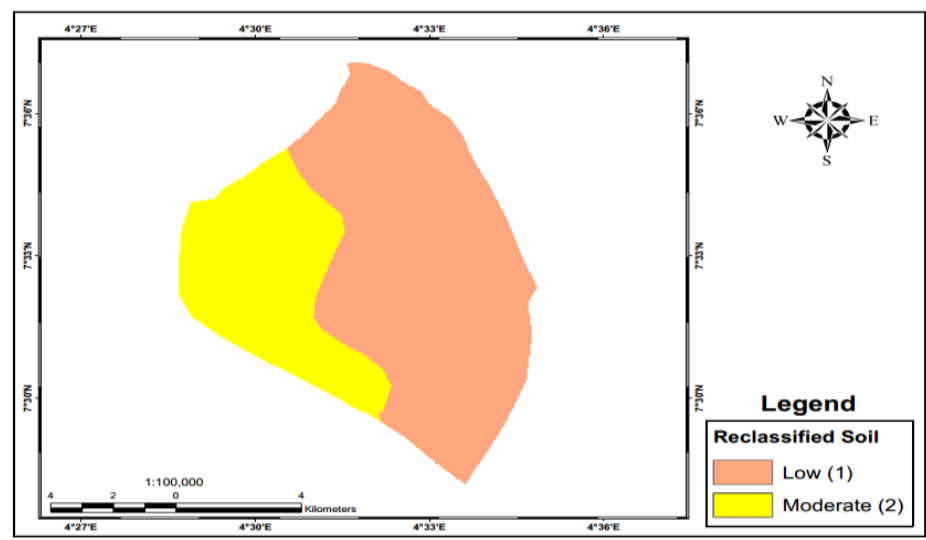

Figure 7: Soil type of the study area

\section{Land cover:}

The land use land cover assessment carried out showed six classes, which include; water body, builtup areas, bare land, grassland, bushland and forest covers as shown in Figure 8. Forest, bushland/grassland stores water and reduce the runoff of rainwater. Land cover classes were reclassified according to their respective preference values. Figure 9 shows the reclassified land cover map. 


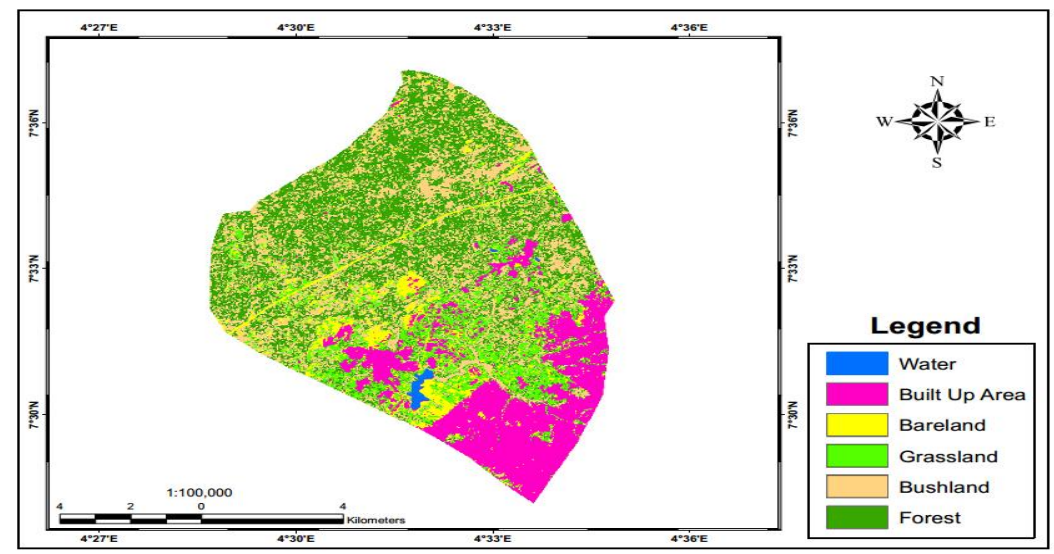

Figure 8: Land cover map of the study area

Table 7: Unified preference value for land cover

\begin{tabular}{llll}
\hline Land cover & Preference Value & Unified Value & Flood vulnerability class \\
\hline Forest & 1 & 25 & Low \\
Bushland & 1 & 25 & Low \\
Grass Land & 2 & 50 & Moderate \\
Bare surface & 3 & 75 & High \\
Built-up Area & 3 & 100 & High \\
Water & 4 & 100 & Very high \\
\hline
\end{tabular}

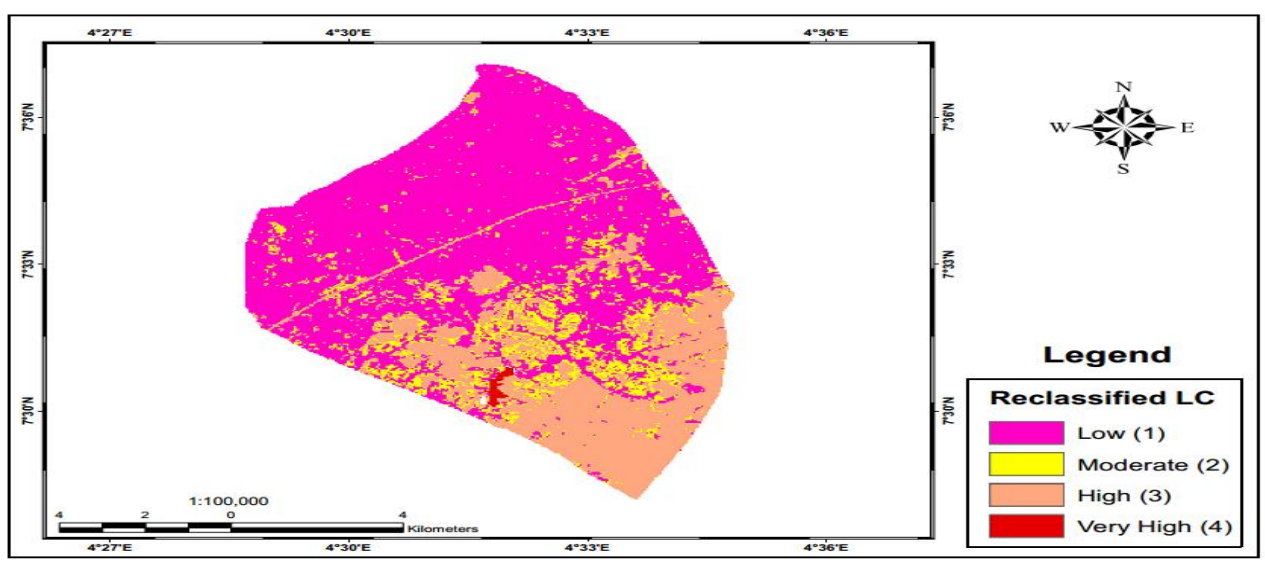

Figure 9: Reclassified land cover map of the study area

\subsection{Multi-criteria decision making}

Using the Weighted Linear Combination (WLC) method, all the map layers (the factors) were overlaid in the final GIS spatial analysis for flood vulnerability zones simulation. The WLC technique was carried out using ArcGIS software. The output of this WLC method produced a map that simulated the most potential flood susceptible zones for flood vulnerability mapping.

\subsection{Data quality}

To ensure the quality of the data utilized, accuracy assessments were carried out on the land cover classification. The overall classification accuracy was $86.8 \%$. Furthermore, rainfall station data of some points (10 points) within the study area obtained from the Nigerian Meteorological (NIMET) Agency were plotted against the rainfall data obtained from the Tropical Rainfall Measuring Mission (TRMM) to validate the accuracy of the rainfall data obtained from TRMM. The correlation coefficient $\left(\mathrm{r}^{2}\right)$ between the TRMM data and NIMET data was 0.85 , indicating that there was a strong or almost perfect positive correlation between the rainfall data from both sources. Also, elevation data obtained through ground technique were used in validating the accuracy of the elevation data obtained from the Shuttle Radar Topography Mission (SRTM). The correlation coefficient $\left(r^{2}\right)$ between the SRTM and ground data was 0.76 , thereby indicating a strong positive correlation between the two 
data from disparate sources. Ground truthing was carried out to validate the flood hazard maps produced from the AHP model.

\subsection{Results and Discussions}

Datasets including coordinates of points, DEM, soil, land use, and precipitation were structured, reclassified and symbolized using ArcGIS 10.4. The results of the processes show the criteria for flood risk and various ranking of each objective. Subsequent steps show how the flood hazard maps and flood risk vulnerability maps were produced using.

\subsection{Pairwise comparison}

Table 8, Table 9 and Table 10 shows the results of the pairwise comparison, ranking of the criterion and the interpretation of symbols used in depicting the different factors.

$E_{(1,1)} E_{(1,2)} E_{(1,3)} \quad \ldots E_{(1, n)}$

$E_{(2,1)} E_{(2,2)} E_{(2,3)} \cdots E_{(2, n)}$

$E_{(n, 1)} E_{(n, 2)}\left(E_{(n, 3)} \quad \ldots E_{(n, n)}\right.$

Table 8: Matrix of pair-wise comparisons of the six criteria for the AHP process

\begin{tabular}{|l|l|l|l|l|l|l|}
\hline & C1 & C2 & C3 & C4 & C5 & C6 \\
\hline C1 & 1.00 & 2.00 & 3.00 & 4.00 & 5.00 & 6.00 \\
\hline C2 & 0.50 & 1.00 & 1.50 & 2.00 & 2.50 & 3.00 \\
\hline C3 & 0.33 & 0.67 & 1.00 & 1.33 & 1.67 & 2.00 \\
\hline C4 & 0.25 & 0.50 & 0.75 & 1.00 & 1.25 & 1.50 \\
\hline C5 & 0.20 & 0.40 & 0.6 & 0.80 & 1.00 & 1.20 \\
\hline C6 & 0.17 & 0.33 & 0.5 & 0.67 & 0.83 & 1.00 \\
\hline SUM & 2.45 & 4.90 & 7.35 & 9.80 & 12.25 & 14.70 \\
\hline \multicolumn{7}{|c|}{ Source: Author, 2018) } \\
\hline
\end{tabular}

Table 9: Determined relative criterion weights

\begin{tabular}{|l|l|l|l|l|l|l|l|l|}
\hline & C1 & C2 & C3 & C4 & C5 & C6 & WEIGHTS & PERCENT\% \\
\hline C1 & 0.41 & 0.41 & 0.41 & 0.41 & 0.41 & 0.41 & 0.41 & $41 \%$ \\
\hline C2 & 0.20 & 0.20 & 0.20 & 0.20 & 0.20 & 0.20 & 0.20 & $20 \%$ \\
\hline C3 & 0.14 & 0.14 & 0.14 & 0.14 & 0.14 & 0.14 & 0.14 & $14 \%$ \\
\hline C4 & 0.10 & 0.10 & 0.10 & 0.10 & 0.10 & 0.10 & 0.10 & $10 \%$ \\
\hline C5 & 0.08 & 0.08 & 0.08 & 0.08 & 0.08 & 0.08 & 0.08 & $8 \%$ \\
\hline C6 & 0.07 & 0.07 & 0.07 & 0.07 & 0.07 & 0.07 & 0.07 & $7 \%$ \\
\hline SUM & 1.00 & 1.00 & 1.00 & 1.00 & 1.00 & 1.00 & 1.00 & $100 \%$ \\
\hline \multicolumn{10}{|c|}{ (Source: Author, 2018) } \\
\hline
\end{tabular}

Table 10: Interpretation of criteria symbols

\begin{tabular}{|l|l|l|}
\hline Criteria no. & Criteria & Weight \\
\hline C1 & Rainfall & 0.41 \\
\hline C2 & Land cover & 0.20 \\
\hline C3 & Slope & 0.14 \\
\hline C4 & Elevation & 0.10 \\
\hline C5 & Drainage density & 0.08 \\
\hline C6 & Soil type & 0.07 \\
\hline
\end{tabular}

(Source: Author, 2018)

\subsection{Flood hazard of Ife-Central L.G.A.}

The combination of all parameters was carried out in GIS using the WLC method. This was based on the weights generated from the AHP. The WLC formula is shown in Equation 2.

$$
W L C=\frac{1}{n} \sum_{i=0}^{n} D i W i
$$


where:

WLC Weighted linear combination

$n \quad$ Numbers of parameters,

$D_{i} \quad$ Decision parameter and

$W_{i} \quad$ AHP weight (Ouma and Tateishi, 2014).

Using the raster calculator of ArcGIS, the calculated weights obtained from pairwise matrix of AHP for each criterion was applied on the various raster criteria in the WLC equation to obtain the flood hazard associated with every location in Ife-Central LGA. From the flood hazard map shown in Figure 10, areas with very high hazard are shown in red, and areas associated with low flood hazard are shown in white.

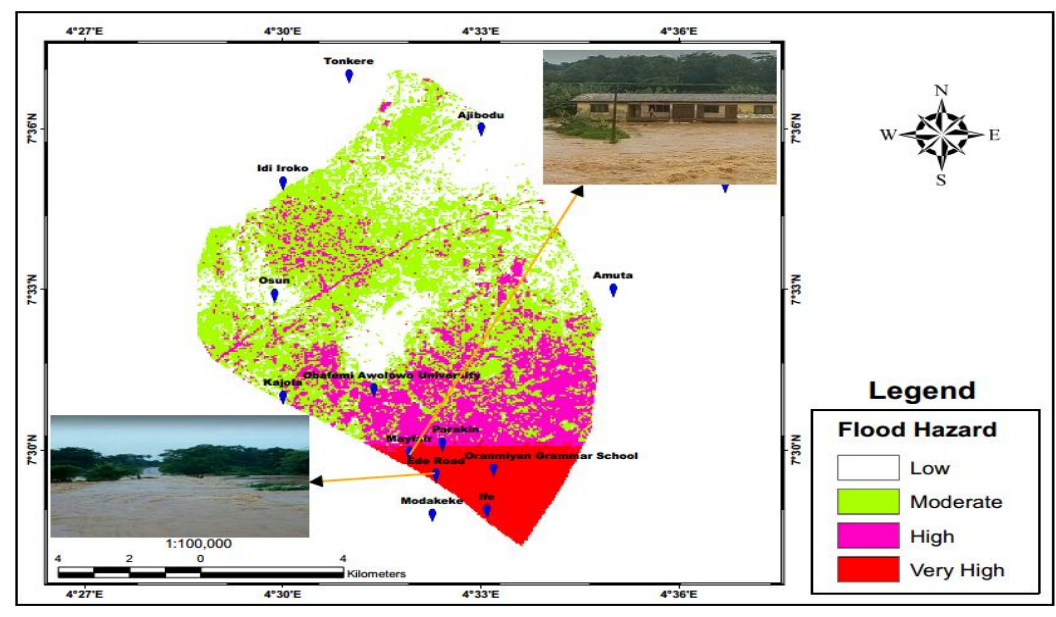

Figure 10: Flood hazard map of Ife Central L.G.A

The very high hazard areas covered $10.113 \mathrm{~km}^{2}(9.2 \%)$, the high hazard areas covered $22.545 \mathrm{~km}^{2}$ (20.4\%), the moderate hazard areas covered $48.968 \mathrm{~km}^{2}(44.3 \%)$ and the low hazard areas covered $28.813 \mathrm{~km}^{2}(26.1 \%)$ as shown in Table 11. The percentage of various classes of flood hazard is shown in Figure 11.

Table 11: Flood vulnerability area

\begin{tabular}{lll}
\hline Flood hazard class & Area $(\mathrm{sq} . \mathrm{km})$ & Area $(\%)$ \\
\hline Low & 28.813 & 26.1 \\
Moderate & 48.968 & 44.3 \\
High & 22.545 & 20.4 \\
Very high & 10.113 & 9.2 \\
\hline \multicolumn{3}{c}{}
\end{tabular}

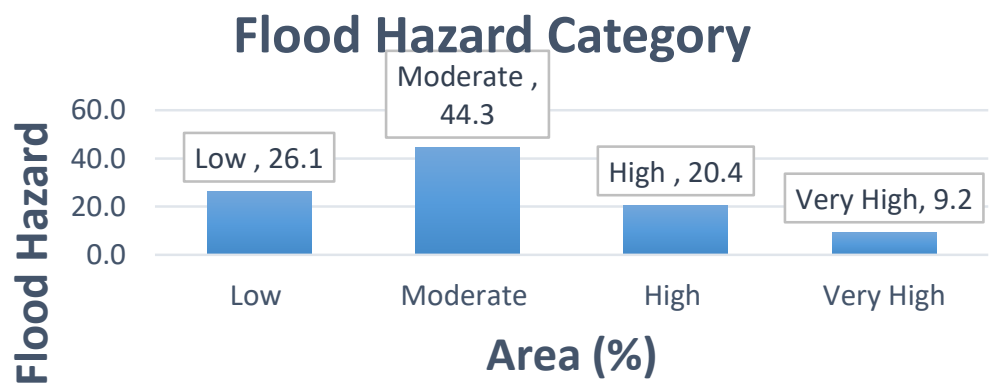

Figure 11: Percentage of flood hazard

\subsection{Flood vulnerability of Ife-Central L.G.A.}

A flood vulnerability map was produced in order to determine, delineate and map the spatial extent of water coverage and vulnerability to flooding in the area. The built-up area within the study area was overlaid on the flood hazard map to view and calculate the extent of the built-up area vulnerable to flood. Based on the land cover classification exercise carried out, the total area of built-up area in Ife 
Central LGA is $20.897 \mathrm{~km}^{2}$. The area of the built-up that falls under very high hazard category is $4.764 \mathrm{~km}^{2}$ and $5.100 \mathrm{~km}^{2}$ area of the built environment falls under high hazard category making those areas vulnerable to flood. The vulnerability of built-up areas to flooding was produced in a map shown in Figure 12 and the percentages of built-up vulnerable to flood are shown in Table 12.

Table 12: Built-up areas vulnerable to flood

\begin{tabular}{lll}
\hline Flood hazard class & Area (sq. Km) & Area (\%) \\
\hline High & 5.100 & 24.4 \\
Very high & 4.764 & 22.8 \\
\hline
\end{tabular}

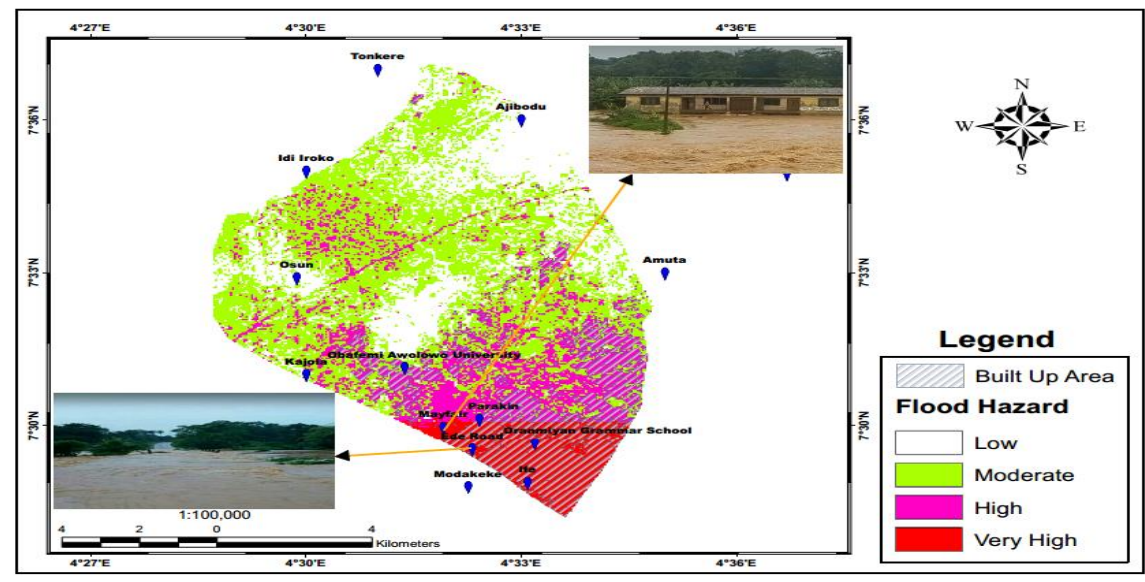

Figure 12: Vulnerability to flooding in Ife Central L.G.A

It was deduced that $47.2 \%$ of the total built-up areas in the study area are vulnerable to flood.

\subsection{Validation of pairwise matrix of the AHP model}

The results of the AHP model were validated using the Consistency Ratio index shown in Equation 4. Table 13 shows the determining of Consistency Ratio and Table 14 shows the Random Inconsistency Indices: Where, $\mathrm{C} 1$ = Rainfall; $\mathrm{C} 2$ = Land cover; C3 = Slope; C4 = Elevation; C5= Drainage density; C6 $=$ Soil.

The final consistency ratio (CR), from which the evaluations of the pairwise comparison matrix were determined was obtained as the ratio of the Consistency Index and the Random Index (RI).

Table 13: Determined consistency index (CI)

\begin{tabular}{|l|l|l|l|l|l|l|}
\hline \multicolumn{2}{|l|}{ Step 1 } \\
\hline C1 & 1.00 & 2.00 & 3.00 & 4.00 & 5.00 & 6.00 \\
\hline C2 & 0.50 & 1.00 & 1.50 & 2.00 & 2.50 & 3.00 \\
\hline C3 & 0.33 & 0.67 & 1.00 & 1.33 & 1.67 & 2.00 \\
\hline C4 & 0.25 & 0.50 & 0.75 & 1.00 & 1.25 & 1.50 \\
\hline C5 & 0.20 & 0.40 & 0.6 & 0.80 & 1.00 & 1.20 \\
\hline C6 & 0.17 & 0.33 & 0.5 & 0.67 & 0.83 & 1.00 \\
\hline
\end{tabular}

\begin{tabular}{|l|l|l|l|l|l|l|}
\hline Weight & 0.41 & 0.20 & 0.14 & 0.10 & 01.08 & 0.07 \\
\hline
\end{tabular}

STEP 2: SUM 1/WEIGHT

\begin{tabular}{|l|l|l|l|l|l|l|l|}
\hline \multicolumn{7}{|c|}{} & SUM 1 \\
\hline C1 & 0.41 & 0.40 & 0.42 & 0.40 & 0.40 & 0.42 & 2.45 \\
\hline C2 & 0.21 & 0.20 & 0.21 & 0.20 & 0.20 & 0.21 & 1.23 \\
\hline C3 & 0.14 & 0.13 & 0.14 & 0.13 & 0.13 & 0.14 & 0.81 \\
\hline C4 & 0.10 & 0.10 & 0.11 & 0.10 & 0.10 & 0.11 & 0.62 \\
\hline C5 & 0.08 & 0.08 & 0.08 & 0.08 & 0.08 & 0.08 & 0.48 \\
\hline C6 & 0.07 & 0.07 & 0.07 & 0.07 & 0.07 & 0.07 & 0.42 \\
\hline
\end{tabular}
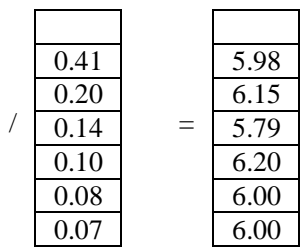

$=$

$$
\text { Sum } 2 \text { 36.12 }
$$

Table 14: Random index (RI) used to compute consistency ratios (CR)

\begin{tabular}{|l|l|l|l|l|l|l|l|l|l|l|}
\hline $\mathrm{N}$ & 1 & 2 & 3 & 4 & 5 & 6 & 7 & 8 & 9 & 10 \\
\hline Random index (RI) & 0 & 0 & 0.58 & 0.90 & 1.12 & 1.24 & 1.32 & 1.41 & 1.45 & 1.49 \\
\hline
\end{tabular}


The measure of departure from consistency (Consistency Index) was as well calculated using Equation 3.

$C I=\frac{\lambda-n}{n-1}$

where:

$n \quad$ Number of factors (i.e. 6), and

$\lambda \quad$ Average value of the consistency vector determined in the above step.

$\lambda=5.98+6.15+5.79+6.20+6.00+6.00=36.12 / 6=6.02$

Based on Equation (3) $\mathrm{CI}=6.02-6 / 6-1=0.004$

In order to assess the robustness of the expert view, the Consistency Ratio (CR) was calculated using Equation 4.

$C R=\frac{C I}{R I}$

Where:

RI Random Inconsistency Index whose value depends on the number (n) of factors being compared; for $\mathrm{n}=6, \mathrm{RI}=1.24$ as illustrated in Table 14

Using Equation (4),

$C R=\frac{0.004}{1.24}=0.003$

Thus, since $0.003<0.1$, it indicates that there is a realistic degree of consistency in the pairwise comparison and as a result, the weights $0.41,0.20,0.14,0.10,0.08,0.07$ (i.e. $41,20,14,10,8$ and $7 \%$ respectively) can be assigned to rainfall, land cover, slope, elevation, drainage density and soil type respectively.

\subsection{Conclusion}

Based on the results of this case study, the aim of the project has been achieved by producing the flood hazard and vulnerability maps of Ife Central LGA showing areas prone to flood, which will help both decision-makers and inhabitants of the areas that fall under high prone areas within the study area. The result showed very high hazard areas covered $10.113 \mathrm{~km}^{2}(9.2 \%)$, the high hazard areas covered $22.545 \mathrm{~km}^{2}(20.4 \%)$, the moderate hazard areas covered $48.968 \mathrm{~km}^{2}(44.3 \%)$ and the low hazard areas covered $28.813 \mathrm{~km}^{2}(26.1 \%)$. The method adopted correctly identifies all existing flood incidence areas within the flood-prone areas in the hazard map. It was discovered that based on the land cover classification exercise conducted, areas prone to flood are basically areas with low elevation. Out of the total area of built up in Ife Central LGA which is about $20.897 \mathrm{~km}^{2}$,the area of the built-up, that falls under very high hazard category is $4.764 \mathrm{~km}^{2}(24.4 \%)$ and $5.100 \mathrm{~km}^{2}(22.8 \%)$ area of the built environment falls under high hazard category making these areas vulnerable to flood.

Flood hazard and vulnerability maps are valuable tools used by planners, insurers and emergency service operators for assessing flood. Decision-makers need to assess risk for more than one scene so as to take appropriate measures in alleviating the problem. In the light of the above discussion, flood mapping, being an important measure of flood management technique will go a long way in reducing flood damages in areas frequently affected. Flood frequency analysis of peak hydrological data yields the return periods of major peak discharges and the probability of occurrence of flood; specified return period helps to provide preparedness to cope with such peaks. Flood model combined with GIS was found to be very important to map out the likely inundated areas of a given catchment. The study has shown that a flood vulnerability map can be produced for flood-prone areas in a short time with the use of GIS and Remote Sensing. Thus, the appropriate and early solution could be implemented and can increase public awareness of flood event. 
The study further recommends that:

i. Proper awareness of various practices that aid flooding such as; dumping of refuse on water channels, erection of structures on water channels, etc. should be conducted in affected communities i.e. communities that fall under high and very high flood hazard classes.

ii. The Government should assist inhabitants of the affected communities by constructing new drainages and rehabilitating the existing drainages which will channel runoffs in the area efficiently to proximate streams.

\section{References}

Alfred, O. (2018). Osun blames federal government as floods hit Ile-Ife. Retrieved February 15, 2020, from https://campusreporter.ng/osun-blames-federal-government-as-floods-hit-ile-ife/

Climate-Data.org. (n.d.). Ife climate: Average Temperature, weather by month, Ife weather averages. Retrieved March 1, 2020, from https://en.climate-data.org/africa/nigeria/osun/ife-386976/

Dor, K. (2017). Essentials of Environmental Science.

Klemas, V. (2015). Remote Sensing of Floods and Flood-Prone Areas: An Overview. Journal of Coastal Research, 314, pp. 1005-1013.

Komolafe, A. A., Adegboyega, S. A. A., and Akinluyi, F. O. (2015). A review of flood risk analysis in Nigeria. American Journal of Environmental Sciences, 11(3), pp. 157-166.

Orimoogunje, O., Fashae, O. A., Oke, T. and Akinwumiju, A. S. (2016). Flood Vulnerability in a Part of Southwestern Nigeria. Academia Journal of Environmental Science, 4(3), pp. 55-61.

Ouma, Y. O. and Tateishi, R. (2014). Urban flood vulnerability and risk mapping using integrated multi-parametric AHP and GIS: Methodological overview and case study assessment. Water (Switzerland), 6(6), pp. 1515-1545.

Saaty, T. L. (2008). Decision making with the analytic hierarchy process. Int. Journal of Services Sciences, 1(1), pp. 83-98.

\section{Cite this article as:}

Ijaware V. A., 2020. GIS based Flood Vulnerability Studies for Ife Central Local Government Area, Osun State, Nigeria. Nigerian Journal of Environmental Sciences and Technology, 4(1), pp. 160-171. https://doi.org/10.36263/nijest.2020.01.0184 